\title{
Clinical presentation and outcome of ectopic pregnancy
}

\author{
Mohammed Sidhiq Chundakkadan*, Chandramathy K., Neethu Selvest
}

Department of Obstetrics and Gynecology, Government Medical College, Kozhikode, Kerala, India

Received: 20 July 2021

Revised: 11 August 2021

Accepted: 12 August 2021

\author{
*Correspondence: \\ Dr. Mohammed Sidhiq Chundakkadan, \\ E-mail: cmsidhiq@gmail.com
}

Copyright: (C) the author(s), publisher and licensee Medip Academy. This is an open-access article distributed under the terms of the Creative Commons Attribution Non-Commercial License, which permits unrestricted non-commercial use, distribution, and reproduction in any medium, provided the original work is properly cited.

\begin{abstract}
Background: An ectopic pregnancy is defined as blastomere implants anywhere other than the endometrial lining of the uterine cavity. The incidence was around 1-1.5\%. Commonest site in fallopian tube (95\%). Even the incidence was small, it accounted for $3 \%$ of the pregnancy related deaths. The objective of this study was to evaluate the clinical presentation of various types of ectopic pregnancy, any risk factors, various types of management and the outcome.

Methods: This was a prospective COHORT study of 102 ectopic patients admitted at government medical college, Kozhikode during 18 November 2020 to 17 August 2021 with various clinical manifestations. Depends on clinical features, USG findings and HCG estimation, patients were treated by expectant, medical and surgical management. Patients followed up for 2 weeks after discharge.

Results: 102 cases were admitted in study period. 98 cases were tubal ectopic. $69.6 \%$ with history of various risk factors. Commonest age group was $26-35$ years. $70.6 \%$ were multiparous. HCG $<5000$ responded very well to medical management ( $92.8 \%$ success rate).

Conclusions: Most common ectopic pregnancy is tubal ectopic and commonly associated with various risk factors. Triad of symptoms will be present in most cases. Early antenatal visit will reduce the number of ruptured ectopic. Careful selection of cases by HCG value and size of ectopic will give excellent result.
\end{abstract}

Keywords: Ectopic pregnancy, Methotrexate, HCG, Salpingectomy, Heterotropic pregnancy, Gefitinib

\section{INTRODUCTION}

Ectopic pregnancy is defined as pregnancy outside uterine cavity. The Greek word ectopic means out of place or displaced. It is a life threatening emergency encountered by medical practitioners. About $1-1.5 \%$ pregnancy are ectopic. $95 \%$ of ectopic pregnancy was in the fallopian tube. The other sites of ectopic pregnancy are ovarian pregnancy, cervical, caesarean section scar ectopic and abdominal pregnancies. Even though the incidence is small, ectopic pregnancy accounts around 3\% of pregnancy related deaths. Incidence of ectopic pregnancy is increasing in UK and USA. Incidence in India is reported to be 1 in 3000 by ICMR. This is partly due to improved diagnosis. The first successful surgical treatment of ectopic pregnancy is by Tail in 1883 . He performed salpingectomy in 4 cases and all of them survived. Availability of pregnancy test in 1960 and ultrasound scan in 1970 were significant advances for early diagnosis and management of ectopic pregnancy.

Risk factors for increased incidence of EP includes tubal factors, zygote abnormalities, ovarian factors and intrauterine contraceptive device. Previous tubal surgeries, recanalization after tubal sterilisation, previous history of ectopic pregnancy, pelvic inflammatory disease, in vitro fertilisation (upto 28\%) and smoking are other risk factors. A higher proportion of ovarian pregnancy has been seen in IUCD users 5.5\% Breen et al 1970 and Raziel et al 1990). ${ }^{1,2}$ ART increased the risk of ectopic pregnancy approximately $2.5-5 \% .^{3}$ Decreased ovarian reserve is an independent risk factor. ${ }^{4}$ 
Classical clinical triad of presentation is delayed menstruation, abdominal pain and vaginal bleeding or spotting. In $25 \%$ or more cases history of amenorrhoea is not obtained. Ectopic pregnancy presents with vaginal bleeding in $40-50 \%$ cases. Bleeding is usually scanty and may be continuous or intermittent. It can also cause intraperitoneal bleeding leading to hypotension, tachycardia and declining haematocrit. It can also present with pain in abdomen. Pain may be severe or mild, upper or lower abdomen, unilateral or bilateral. Pain can be referred to shoulder in case of ruptured ectopic due to diaphragmatic irritation. In case of series of ectopic pregnancy, $98.6 \%$ present with abdominal pain, $74.1 \%$ amenorrhea and $56.4 \%$ with irregular bleeding. ${ }^{5}$ Patient also present with nausea, vomiting, sudden fainting attacks.

Diagnosis is by physical findings, transvaginal sonogram, serum $\square$ HCG measurement and diagnostic laparoscopy. Physical findings may be normal before rupture. In a case of ruptured ectopic pregnancy there may be hypotension and tachycardia due to hypovolemia. Sudden pallor is pathognomonic feature of ruptured ectopic pregnancy. On abdominal examination there may be tenderness, slightly enlarged uterus and shifting dullness etc. may be present. On $\mathrm{P} / \mathrm{V}$ examination cervical movement tenderness may be present.

HCG measurement is the corner stone of diagnosis and management. Doubling time of $\square$ HCG over 48 hours is $>66 \%$ in intrauterine pregnancy. But in $15 \%$ of ectopic pregnancy there may be $>66 \%$ rise in 48 hours and $15 \%$ normal pregnancies it will be less than $66 \%$.

Transvaginal ultrasound is the diagnostic tool of ectopic pregnancy. An empty uterus, detection of adnexal mass, hemoperitoneum and visualisation of gestational sac, fetal pole and cardiac activity in adnexa is most specific sign of ectopic pregnancy. ${ }^{6,7}$ Tranvaginal sonogram and transabdominal sonogram can detect $38 \%$ and $22 \%$ adnexal ring respectively. ${ }^{8}$

\section{Management}

The management is mainly divided into expectant medical and surgical management depends on the vitals of patient, ultrasound findings, site of ectopic and beta HCG measurement. Laparoscopic salpingostomy or salpingectomy is the ideal surgical management. Laparotomy is indicated when patient is hemodynamically unstable, cornual/interstitial pregnancy and abdominal pregnancy. Laparoscopic management of cornual pregnancy is becoming common among skilled surgeon. ${ }^{9}$ Expectant management can be tried when HCG value is $<1500$, sac size $<2 \mathrm{~cm}$ and patient is stable.

\section{Medical management}

Methotrexate is most commonly used drug. Other agents like $\mathrm{KCl}$, mifepristone were studied but not used commonly. Stable patient with $\square \mathrm{HCG}<10,000$, sac size less than $4 \mathrm{~cm}$, fetal heart not detected cases were taken for medical management (ACOG 2009 guidelines). ${ }^{10}$ Methotrexate usually given IM injection after CBC, RFT and LFT estimation.

\section{Methotrexate multidose regimen}

Methotrexate $1 \mathrm{mg} / \mathrm{kg}$ IM was given on 1, 3, 5, 7 days and leucovorin $0.1 \mathrm{mg} / \mathrm{kg}$ given on $2,4,6,8$ days. HCG measured on 1, 3, 5, 7 days and if HCG declined by $15 \%$, stop methotrexate and monitor HCG weekly until non pregnant level reached.

Single dose regime: Methotrexate $50 \mathrm{mg} / \mathrm{m}^{2}$ on day 1 and HCG measured on day 4 and 7.

Two dose regime: Methotrexate on day 1 and 4 and measure HCG on day 4 and 7, if HCG dropped by $15 \%$, monitor HCG weekly until non pregnant level.

When comparing management to laparoscopic salpingostomy, the multidose had similar success rate. ${ }^{11}$ Comb et al reported $93 \%$ success with single dose methotrexate when adnexal mass was $<3.5 \mathrm{~cm}, 87-90 \%$ when $>3.5 \%$.

\section{Heterotopic pregnancy}

When ectopic pregnancy existed with intrauterine pregnancy and the incidence was 1 in 1000 to 1 in $30000 .^{12}$ Patients undergoing ART had a higher incidence.

\section{Objectives}

The objective of this study was to understand the proportion of known risk factors, the clinical presentation of ectopic pregnancy and to study the outcome of different types of management of ectopic pregnancy.

\section{METHODS}

This was a prospective COHORT study of ectopic pregnancy patients admitted in the department of OBG, government medical college, Kozhikode during November 2020 to May 2021. Data regarding demographic profile, clinical features were taken. General examination, abdominal and pervaginal examination was done to assess severity of symptoms and needed for immediate treatment. Then patients were investigated, routine blood investigation, HCG, abdominal and transvaginal sonogram done to detect haemoperitoneum, evaluation of uterus, ovary and tubes. Unstable patients and ruptured ectopic pregnancies were taken for surgical treatment.

Patient with minimal symptoms and HCG <1500 mIU were taken for expectant management. If symptoms were aggravating or HCG in increasing was considered as failed expectant and taken for medical management. 
In medical management after routine blood investigations RFT and LFT, injection methotrexate was given. HCG measured 0, 4 and 7th day. If value was increasing, 2nd dose methotrexate or multiple dose was given. Still value was increasing, it was considered as failed medical treatment.

Data regarding demographic profile, signs and symptoms were collected. Known risk factors like previous history of ectopic pregnancy, PID, tubal surgeries, infertility treatment, IUCD use, smoking were collected.

\section{Statistical analysis}

Statistical analysis was done by using SPSS software version 20. Data was expressed as frequencies and percentages. Chi square test was used for analysis of data.

\section{RESULTS}

During the study period from November 2020 to May 2021, there were 102 cases of ectopic pregnancies were studied. The baseline demographic details are shown in Table 1 and 2.

Among the cases, 19-25 years were 30 cases (29.4\%), 2635 years were 57 cases $(55.8 \%)$ and $>36$ years of 15 cases $(14.7 \%)$.
Out of the total 102 cases of ectopic pregnancy, 98 cases were tubal ectopic and 3 cases of scar ectopic and one cervical pregnancy. Majority of ectopic pregnancy are tubal ectopics $98 \%$.

Management was decided on the basis of presentation, vitals of patient, type of ectopic, HCG values and size of ectopic. Expectant management were done for 13 cases of which 12 cases were success $(92.3 \%)$. HCG <3500 and size $<4 \mathrm{~cm}$ were recruited for medical management. 42 cases were recruited and 36 cases $(85.7 \%)$ successfully managed. 36 patients received single dose methotrexate, 4 cases, 2 doses of methotrexate and 2 cases received multiple dose regimen.

Success rate of $92 \%$ when HCG value was $<5000$ and only $71.5 \%$ when $\mathrm{HCG}$ value $>5000 \mathrm{mIU} / \mathrm{ml}$.

We had 3 cases of caesarean scar ectopic and 1 case of cervical pregnancy during the study period. All the 3 cases of CS scar treated with multiple dose regimen of methotrexate and 2 cases were success. One case of scar ectopic resulted in emergency laparotomy and evacuation.

Cervical pregnancy successfully treated with multiple dose methotrexate and gefitinib $250 \mathrm{mg}$ BD for 5 days.

Table 1: Age group of the cases.

\begin{tabular}{|ll|}
\hline Age group (in years) & Number of patients $\mathbf{N}(\%)$ \\
\hline $\mathbf{1 9}-\mathbf{2 5}$ & $30(29.4)$ \\
\hline $\mathbf{2 6 - 3 5}$ & $57(55.8)$ \\
\hline $\mathbf{> 3 5}$ & $15(14.7)$ \\
\hline Total & $102(100)$ \\
\hline
\end{tabular}

Table 2: Parity.

\begin{tabular}{|lll|}
\hline Parity & Frequency & Percentage \\
\hline Primigravida & 30 & 29.4 \\
\hline Multigravida & 72 & 70.6 \\
\hline Total & 102 & 100 \\
\hline
\end{tabular}

Table 3: Site of ectopic pregnancy.

\begin{tabular}{|lll|}
\hline Site of ectopic & Number of cases & Percentage \\
\hline Tubal & 98 & 96.07 \\
\hline Caesarean scar & 3 & 2.94 \\
\hline Cervical & 1 & 0.99 \\
\hline Total & 102 & 100 \\
\hline
\end{tabular}

Table 4: HCG value at cut off $5000 \mathrm{mIU} / \mathrm{ml}$ and success rate of medical management.

\begin{tabular}{|lll|}
\hline Particulars $(\boldsymbol{\beta H C G})$ & Success $(\%)$ & Failed $(\%)$ \\
\hline$<\mathbf{5 0 0 0}$ & $26(92.85)$ & $2(7.15)$ \\
\hline$>\mathbf{5 0 0 0}$ & $10(71.5)$ & $4(28.5)$ \\
\hline
\end{tabular}


Table 5: Risk factors.

\begin{tabular}{|lllll|}
\hline \multirow{2}{*}{ Risk factors } & Yes & & No & Percentage \\
\hline Previous ectopic & Frequency & Percentage & Frequency & 94.1 \\
\hline Tubal sterilisation & 6 & 5.9 & 96 & 80.4 \\
\hline Previous surgery & 20 & 19.6 & 82 & 78.4 \\
\hline IUCD & 22 & 21.6 & 80 & 96.1 \\
\hline Subfertility treatment & 4 & 3.9 & 98 & 89.2 \\
\hline Spouse smoking & 11 & 10.8 & 91 & 92.2 \\
\hline
\end{tabular}

Table 6: Management.

\begin{tabular}{|llll|}
\hline Management & Outcomes & Failed (\%) & Total $(\%)$ \\
\hline Expectant management & Success (\%) & $1(7.7)$ & $13(100)$ \\
\hline Medical management & $12(92.3)$ & $6(14.3)$ & $42(100)$ \\
\hline Surgical management & $36(85.7)$ & 0 & $43(100)$ \\
\hline Total & $43(100)$ & $7(7.1)$ & $98(100)$ \\
\hline
\end{tabular}

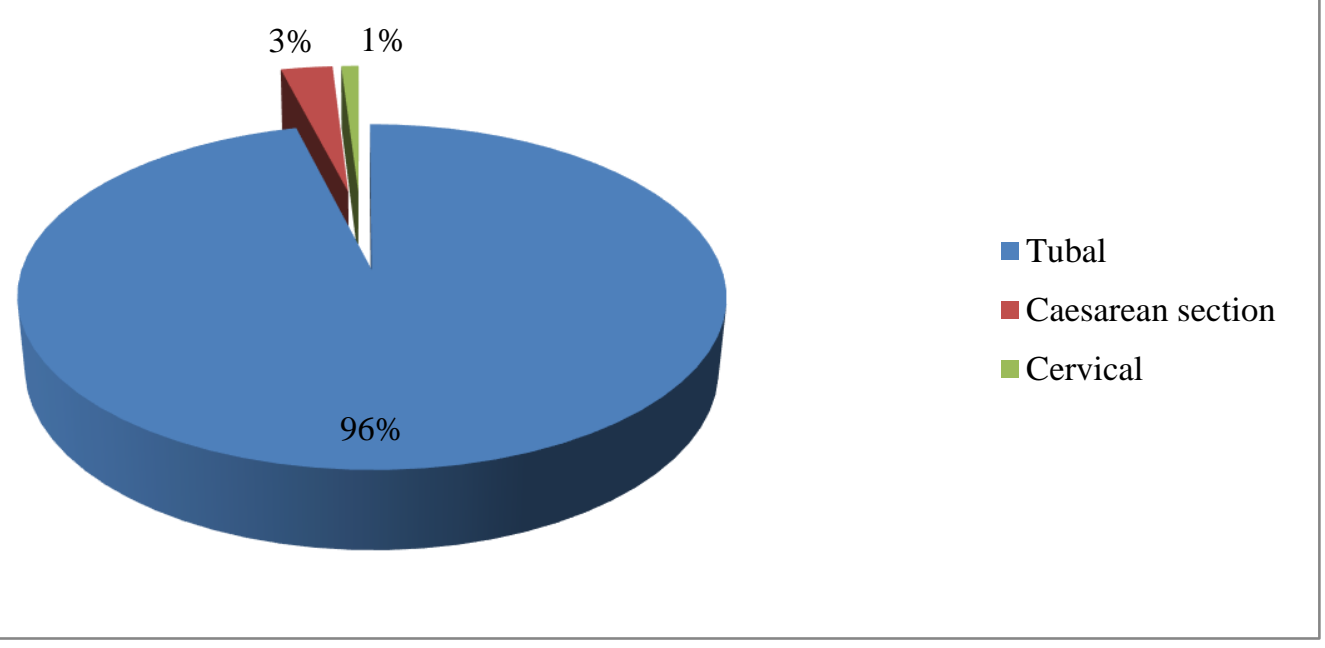

Figure 1: Type of ectopic.

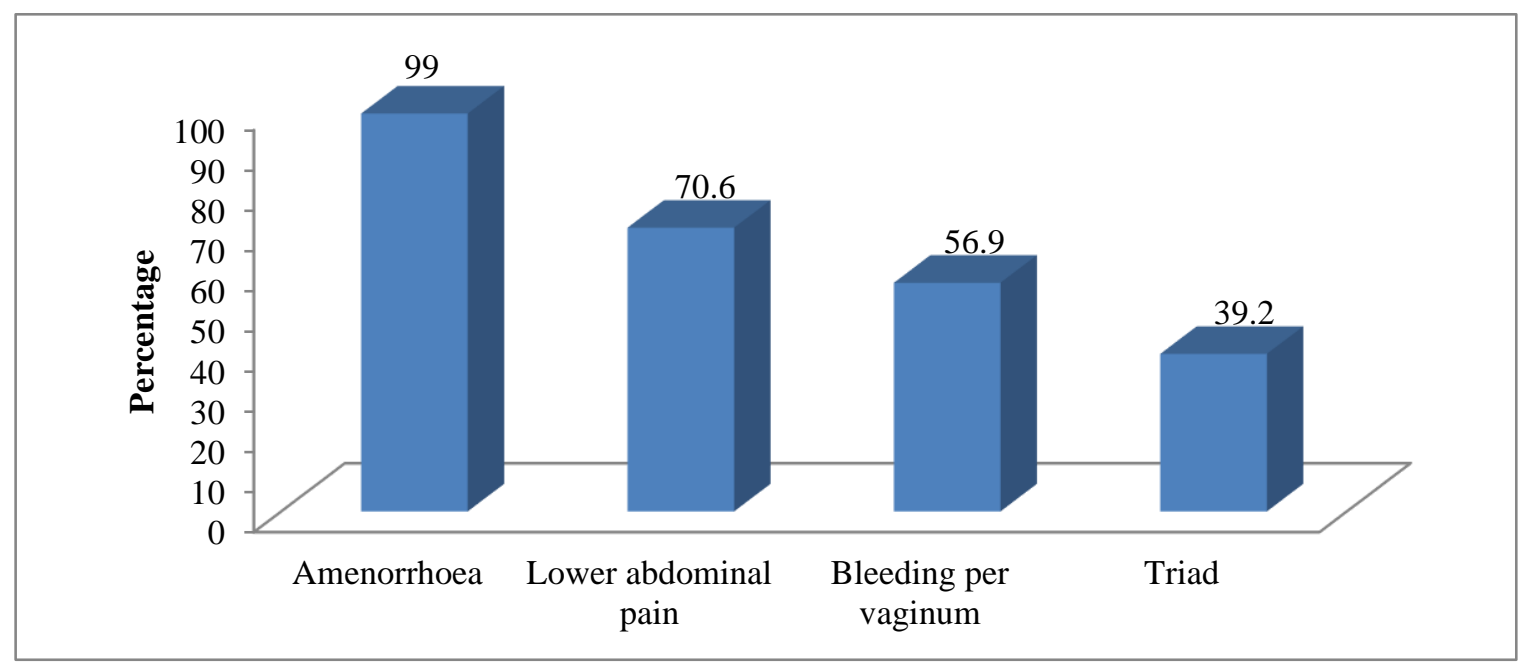

Figure 2: Clinical presentation. 


\section{Surgical treatment}

A total 43 cases managed surgically by laparoscopy/laparotomy. 37 cases directly decided for surgical management. 6 cases of failed medical management and one methotrexate toxicity case were taken for surgical management.

A total 43 patients were for surgery, emergency was 18 patients and elective was 25 patients.

A total 8 cases were laparoscopy and 35 cases were laparotomy.

\section{DISCUSSION}

Ectopic pregnancy still remains a nightmare in spite of advanced diagnostic methods, various medical and surgical management. In our study, mean age was 28.88 (19-44 years). In another similar study mean age 27.9 \pm 7 years. $^{13}$

Majority of patients belonged to 26-35 years (55.8\%). Behera et al reported $54.8 \%$ in 21-30 years age group. ${ }^{14}$ Rate of ectopic pregnancy increased with increasing age.

In this study, $70.6 \%$ were multigravidas and $29.4 \%$ were primigravidas. Multiparous women had higher incidence of ectopic pregnancy due to previous infections, abortions, previous pelvic surgeries. Our study results were similar to Sindhura et al $(72.15 \%){ }^{15}$

In our study, the most common presenting symptoms were amenorrhoea (99\%), abdominal pain (70.6\%) and bleeding $\mathrm{P} / \mathrm{V}(56.9 \%)$. Triad of these symptoms were noted in $39.2 \%$ cases. It was similar to study by Wakankar et al. ${ }^{16}$

At presentation, only 18 patients presented with ruptured ectopic $(17.6 \%)$ and $(78.4 \%)$ were unruptured ectopic. Most of the studies were with high incidence of ruptured ectopic $(84.6 \%)$ Wakaner et al. This could be due to high literacy rate of Kerala who attended antenatal clinic as soon as missing periods and early USG and HCG investigation.

In this study, $69.6 \%$ patients had one or more risk factors. A study by Shah et al in which risk factors were presented in $60.5 \%$ of patients. ${ }^{17}$

In this study, $69.6 \%$ patients had one or more risk factors for ectopic pregnancy. One-third of cases had no risk factors.

In our study, 13 cases of tubal ectopic planned for expectant management, 42 cases for medical management and 43 cases for surgical management. Failure noted in $7.7 \%$ of expectant management and $14.3 \%$ medical management. Failed expectant patients managed medically and failed medical managed surgically. A study by Sargin et al success rate with single dose methotrexate was $76 \%$ and expectant management was $81 \%$. Among medical management, 36 cases treated with single dose methotrexate, 4 cases 2 dose methotrexate and 2 cases by multiple dose methotrexate. One case of medical management abandoned due to toxicity of methotrexate. We had 3 cases of scar ectopic and one case of cervical pregnancy and these cases evaluated separately. Out of which, 2 scar ectopic responded to methotrexate alone.

One case of scar ectopic not responded to methotrexate multiple dose treated with gefitinib $250 \mathrm{mg}$ twice daily for 5 days ends up in surgical evacuation.

Cervical pregnancy responded to multiple dose methotrexate and gefitinib $250 \mathrm{mg}$ twice daily for 5 days. ${ }^{18,19}$

Among surgically managed patients, 18 patients were emergency and 25 cases of elective surgery. 13 patients were ruptured ectopic and 25 cases unruptured. Intraoperatively most common site of ectopic was ampulla $30(69.7 \%)$ followed by isthmus 9 (20.9\%), fimbriae 3 cases $(6.9 \%)$ and scar site $1 \%$.

In a study by Bouyer et al ectopic sites were interstitial $(2.4 \%)$, isthmic $12 \%$, ampullary $70 \%$, fimbrial $11 \%$, ovarian $3.2 \%$ and abdominal $1.3 \%$ were observed. ${ }^{20}$

\section{Limitations}

The main limitation of this study was short duration of the study. Longer duration with larger sample size provided better understanding of management and complications. The role of gefitinib in treatment of ectopic pregnancy needed to be further studied with larger sample size. Also the follow up period of this study was short. Longer follow up period of at least 1 year would have been necessary to study the effect on future fertility in patients with different management options.

\section{CONCLUSION}

In this study, $98 \%$ cases of ectopic were tubal ectopic pregnancy. The most common age group was between 2635 years. The incidence of ectopic pregnancy were more common in multigravidas compared to primigravida. This could be due to previous infections, abortions and previous pelvic surgeries. Among the clinical presentations of ectopic pregnancy, history of amenorrhoea was present in $99 \%$, followed by abdominal pain in $70.6 \%$ and bleeding PV in $56.9 \%$ cases. Triad of these symptoms were noted in $39.2 \%$ cases. Because of the early USG evaluation, only $17.6 \%$ cases presented with ruptured ectopic. $69.6 \%$ cases of ectopic pregnancy had one or more known risk factors. The success rate of expectant and medical management were determined by the $\square$ HCG value and size of ectopic. Even scar ectopic and cervical pregnancies responded well to medical management. Combination of gefitinib with methotrexate can be tried in non-tubal ectopic like scar 
ectopic and cervical pregnancy. This study has emphasized the risk factors which lead to ectopic pregnancy and the importance of early ultrasound for early detection and management of ectopic pregnancy.

\section{ACKNOWLEDGMENTS}

Authors would like to acknowledge all the patients who have contributed to the study.

\section{Funding: No funding sources}

Conflict of interest: None declared

Ethical approval: The study was approved by the Institutional Ethics Committee

\section{REFERENCES}

1. Breen JL. A 21 year survey of 654 ectopic pregnancies. Am J Obstet Gynecol. 1970;106(7):1004-19.

2. Raziel A, Golan A, Pansky M, Ron R, Bukovsky I, Caspi E. Ovarian pregnancy: a report of twenty cases in one institution. Am J Obstet Gynecol. 1990;163:1182-5.

3. Santos-Ribeiro S, Tournaye H, Polyzos NP. Trends in ectopic pregnancy rates following assisted reproductive technologies in the UK: a 12-year nationwide analysis including 160,000 pregnancies. Hum Reprod. 2016;31(2):393-402.

4. Lin S, Yang R, Chi H, Lian Y, Wang J, Huang S, et al. Increased incidence of ectopic pregnancy after in vitro fertilization in women with decreased ovarian reserve. Oncotarget. 2017;8(9):14570-5.

5. Ranji GG, Rani GU, Varshini S. Ectopic pregnancy: risk factors, clinical presentation and management. J Obstet Gynaecol India. 2018;68(6):487-92.

6. Nyberg DA, Hughes MP, Mack LA, Wang KY. Extrauterine findings of ectopic pregnancy of transvaginal US: importance of echogenic fluid. Radiology. 1991;178(3):823-6.

7. Nyberg DA, Mack LA, Laing FC, Jeffrey RB. Early pregnancy complications: endovaginal sonographic findings correlated with human chorionic gonadotropin levels. Radiology. 1988;167(3):619-22.

8. Thorsen MK, Lawson TL, Aiman EJ, Miller DP, McAsey ME, Erickson SJ, et al. Diagnosis of ectopic pregnancy: endovaginal vs transabdominal sonography. Am J Roentgenol. 1990;155(2):307-10.

9. Manea C, Pavlidou E, Urias AA, Jolinière JBDL, Dubuisson JB, Feki A. laparoscopic management of interstitial pregnancy and fertility outcomes after inpsilateral salpingectomy-three case reports. Front Surg. 2014;1:34

10. American College of Obstetricians and Gynecologists. ACOG practice bulletin no. 94: medical management of ectopic pregnancy. Obstet Gynecol. 2008;111(6):1479-85.

11. Mol F, Mol BW, Ankum WM, Veen FVD, Hajenius PJ. Current evidence on surgery, systemic methotrexate and expectant management in the treatment of tubal ectopic pregnancy: a systematic review and meta-analysis. Hum Reprod Update. 2008;14(4):309-19.

12. Reece EA, Petrie RH, Sirmans MF, Finster M, Todd WD. Combined intrauterine and extrauterine gestations: a review. Am J Obstet Gynecol. 1983;146(3):323-30.

13. Ayaz A, Emam S, Farooq MU. Clinical course of ectopic pregnancy: a single-center experience. J Hum Reprod Sci. 2013;6(1):70-3.

14. Behera A, Ghadei R, Bal RN. A clinical study of ectopic pregnancy in a tertiary care hospital. Int $\mathbf{J}$ Reprod Contracept Obstet Gynecol. 2018;7(11):4461.

15. Sindhura M, Sailatha R, Famida AM, Vijayalakshmi K, Sathiya S, Renuka S. Trends in ectopic pregnancy: a retrospective clinical study of 79 cases. Int J Reprod Contracept Obstet Gynecol. 2017;6(7):3009-13.

16. Wakankar R, Kedar K. Ectopic pregnancy-rising trend at Indira Gandhi Government Medical College, Nagpur. Int J Sci Stud. 2015;3(5):18-22.

17. Shah N, Khan NH. Ectopic pregnancy: presentation and risk factors. J Coll Physicians Surg Pak. 2005;15(9):535-8.

18. Skubisz MM, Tong S, Doust A, Mollison J, Johns TG, Neil $P$, et al. Gefitinib and methotrexate to treat ectopic pregnancies with a pre-treatment serum hCG 1000-10,000 IU/L: phase II open label, single arm multi-centre trial. EBioMedicine. 2018;33:276-81.

19. Horne AW, Skubisz MM, Tong S, Duncan WC, Neil $\mathrm{P}$, Wallace EM, et al. Combination gefitinib and methotrexate treatment for non-tubal ectopic pregnancies: a case series. Hum Reprod. 2014;29(7):1375-9

20. Bouyer J, Coste J, Fernandez H, Pouly JL, Job-Spira N. Sites of ectopic pregnancy: a 10 year populationbased study of 1800 cases. Hum Reprod. 2002; 17(12):3224-30.

Cite this article as: Chundakkadan MS, Chandramathy K, Selvest N. Clinical presentation and outcome of ectopic pregnancy. Int J Reprod Contracept Obstet Gynecol 2021;10:3301-6. 